\title{
Correction to: Site response studies in Peshawar using the Nakamura technique of HVSR
}

\author{
Sarfraz Khan ${ }^{1}$ - Muhammad Waseem ${ }^{2}$ - Shoaib Jan ${ }^{1}$ \\ Published online: 23 February 2021 \\ (C) Saudi Society for Geosciences 2021
}

Correction to: Arabian Journal of Geosciences (2021) 14:193 https://doi.org/10.1007/s12517-021-06527-3

This article has an error that was introduced during the publishing process. In this paper, Fig. $5 \mathrm{~b}$ is mistakenly identical to Fig. 5a. The correct Fig. 5a, b and its caption are provided here.

The original article has been corrected.

The online version of the original article can be found at https://doi.org/ $10.1007 / \mathrm{s} 12517-021-06527-3$

Muhammad Waseem

eec_pesh@yahoo.com

1 National Centre of Excellence in Geology, University of Peshawar, Peshawar 25130, Pakistan

2 Department of Civil Engineering, University of Engineering and Technology (UET), Peshawar, KP, Pakistan 

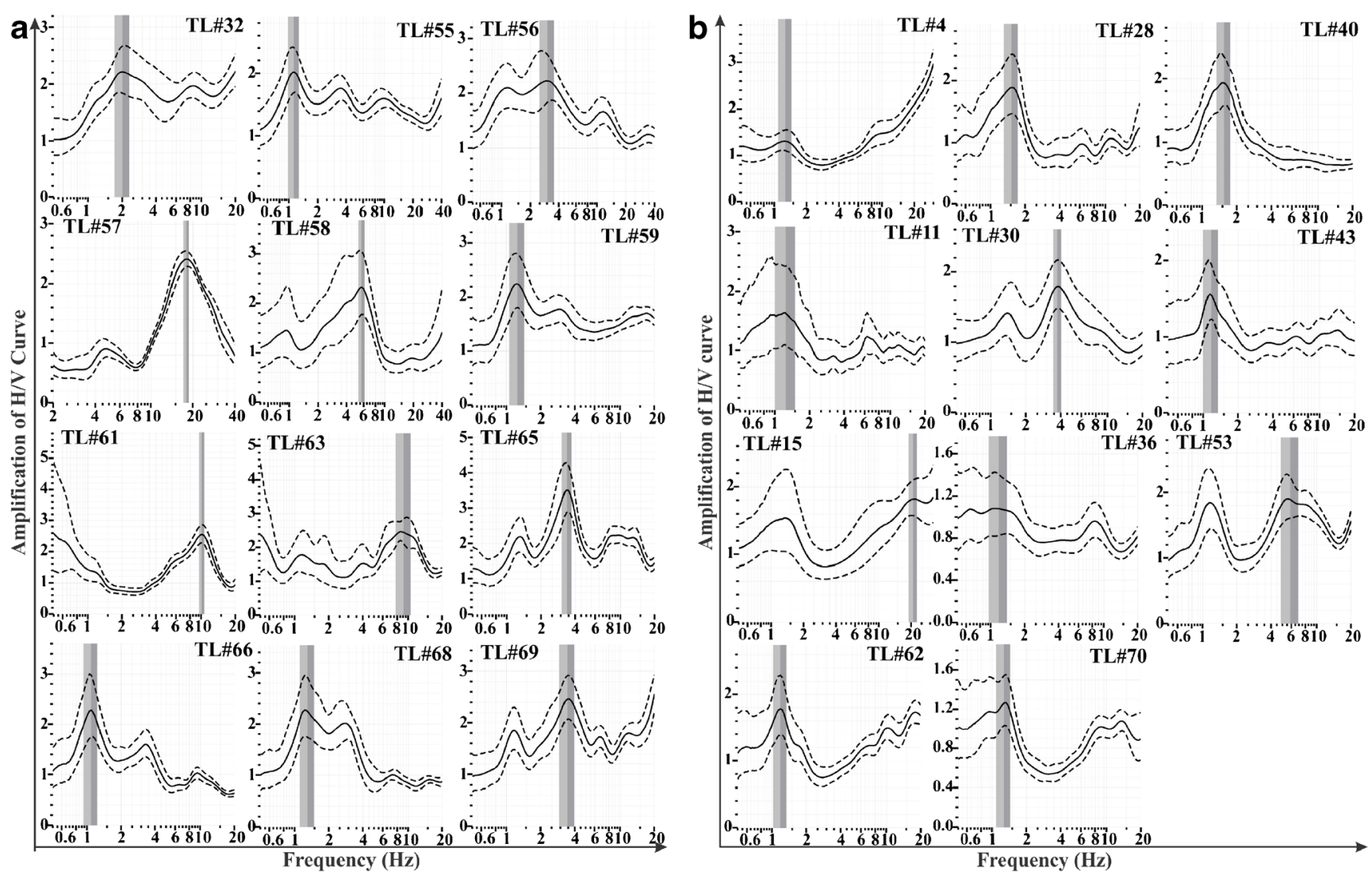